\title{
Ahmed Mohammed, Qian Wang
}

\section{Abstract}

4 It is often a complex task in developing a product distribution plan for a supply chain (SC)

5 network and a supportive decision tool can be useful for easing the role of decision makers.

6 Moreover, it has been increasingly becoming a demand to design a supply chain network

7 considering the environmental impact as a new dimension as required by authorities in many

8 countries. This paper describes a development of a product distribution planner for a three-

9 echelon green meat supply chain (MSC) design in terms of issues which include numbers and locations of facilities that should be opened in association with the product quantity flows. The problem was formulated into a fuzzy multi-objective programming model (FMOPM) with an aim to minimize the total transportation and implementation cost, impact on environment in particularly $\mathrm{CO}_{2}$ emissions and the distribution time of products from farms to abattoirs and from abattoirs to retailers and maximize the average delivery rate in satisfying product quantity as requested by abattoirs and retailers. The model was also formulated for handling the uncertainties of input data of the considered MSC. To optimize the four objectives simultaneously, three solution methods were investigated and used; these include methods of LP-metrics, $\varepsilon$-constraint and goal programming. The best solution by comparing the obtained Pareto solutions was determined using the Max-Min method. The implementation of the developed model based on a case study has also proved its applicability in making an optimal product distribution plan in trade-offs among the four objectives.

Keywords: Distribution plan; Food supply chain design; Fuzzy multi-objective programming; Cost analysis; RFID.

\section{Introduction}


The global demand of food may be doubled by 2050 making food supply chains (FSC) as one of the largest sectors in economy (Accorsi et al., 2016, Mattevi \& Jones, 2016; Fritz \& Schiefer, 2009). Thus, it has been increasingly becoming a major concern for decision makers in supply chain sectors that a robust design of food supply chain network is essential for a success in a competitive market. One of supply chain design tasks involves a strategic decision in a determination in location and allocation of facilities and a strategic decision in quantity flow of products travelling throughout the supply chain network.

Today, environmental issues are equally important and should be taken into account when designing a supply chain network, it may be essential to consider the possibility of incorporating environmental considerations into design of supply chain networks. Besides, in today's competitive economy, many parameters such as cost and potential market demand can vary. Thus, in recent years, issues of uncertainty need also to be taken into account when design a supply chain network (Fattahi et al., 2015; Davis, 1993). A number of researchers applied fuzzy multi-objective optimization methods to tackle the randomness as input data of supply chain networks (Wang \& Hsu, 2010; Qin \& Ji, 2010; Gholamiana et al., 2015). In the context of FSCs, customers have become increasingly concerned about the safety of food they purchase in supermarkets. This has led the supply chain designers to start thinking about implementing a promising technology (e.g. Radio Frequency Identification (RFID)) that aims at maintaining food safety through SCNs. Such a technology is subject to additional cost in investment and should be considered in FSCND.

In this paper, a fuzzy multi-objective optimization model for tackling a planning-distribution problem for a meat supply chain network under multiple uncertainties (e.g. costs, demand and capacity levels of related facilities) was developed. The model aims at minimizing the total transportation and implementation cost, environmental impact $\left(\mathrm{CO}_{2}\right.$ emission $)$ and distribution time of products and maximizing average delivery rate. Furthermore, the impact (in costs) of 

the RFID implementation on the MSC was also investigated. To this aim, the total transportation and implementation cost for the non-RFID-based MSC was formulated as a mono-objective model.

The rest of this article proceeds as follows: section 2 is dedicated to a review of literature. Section 3 presents model development including problem description, notations and model formulation, followed by an optimization strategy thoroughly presented in section 4 . Section 5 shows implementation and evaluation of the developed model. Finally, conclusions are given in section 6.

\section{Literature review}

This section presents prior research works related to three groups including multi-objective optimization in FSCs, fuzzy multi-objective optimization in supply chains and multi-objective optimization in green supply chains.

\subsection{Multi-objective optimization in food supply chains}

There are a few publications in research using multi-objective optimization in the context of FSC management. Rong et al. (2011) developed a mixed integer linear programming model for solving a production and distribution planning problem of a food supply chain. Paksoy et al. (2012) developed a fuzzy multi objective linear programming model for talking a problem of a production-distribution network of an edible vegetable oil manufacturer. Sahar et al. (2014) proposed a multi-objective optimization model of a two-layer dairy supply chain aimed at minimizing $\mathrm{CO}_{2}$ emissions of transportation and the total cost for product distribution. Similar research works were published by Robinson and Wilcox (2008) and Pagell and Wu (2009). Teimoury et al. (2013) developed a multi-objective model for a supply chain of perishable fruits and vegetables. The model used for identifying the best import quota policy of Fruits and Vegetables. García-Flores et al. (2014) presented a mathematical optimization model aims at allocating the optimal location of cattle rest sites and the optimal flows from breeding farms 
to ports, abattoirs and sale-yards. Bortolini et al. (2016) developed a three-objective distribution planner to tackle the tactical optimization issue of a fresh food distribution network. The optimization objectives were to minimize operating cost, carbon footprint and delivery time; the work, however, did not consider other costs and the effect of uncertainty that may occur.

\subsection{Fuzzy multi-objective optimization in supply chains}

More attention focused on the provision of fuzzy programming techniques in the context of solving supply chain network design and distribution problems (Wang \& Hsu, 2010; Qin \& Ji, 2010; Gholamiana et al., 2015). Vidal and Goetschalckx (1997) and Snyder (2006) reviewed supply chain planning-distribution issues in data uncertainty. Petrovic et al. (1998) employed a fuzzy approach applied into a simulation model for a supply chain. The approach was developed to assist in decision making on operational supply chain control parameters in an uncertain environment. The objective was to obtain a compromise between maximization of profit and maximization of service level. Shih (1999) addressed the issue in the cement transportation planning by using fuzzy linear programming approaches. Sakawa et al. (2001) developed a fuzzy mathematical programming model used for minimizing cost of production and transportation of a manufacturer. The model aimed at handling the obscure estimation of parameters for the capacities of the factories and the demands in the regions. Liu and Kn (2004) proposed a method to obtain the membership function of the total transport cost as a fuzzy objective value where the cost coefficients and the supply and demand quantities are considered as imprecise parameters. Wang and Shu (2005) investigated a fuzzy decision strategy that helps tackle the issue of uncertainties of a supply chain. Liang (2006) formulated an interactive fuzzy multi-objective linear programming model to solve fuzzy multi-objective transportation problems. The model objectives were minimizing the total distribution cost and the total delivery time. Wang and Shu (2007) developed a possibilistic model for the supply chain network design. A genetic algorithm was applied to seek near-optimal solutions. Aliev et al. 
(2007) presented a fuzzy integrated multi-period and multi-product production and distribution model of a supply chain network. The model was formulated in terms of fuzzy programming and the solution was provided by a genetic algorithm. Selim et al. (2008) formulated a multiobjective linear programming model for a collaborative production-distribution planning problem in supply chain systems. The model aimed at presenting the optimum facility locations and allocation designs as well as the capacity levels of plants and warehouses that satisfy product quantity requested by retailers. Torabi and Hassini (2009) provided a production plan for a supply chain master planning model consisting of multiple suppliers, one manufacturer and multiple distribution centers. The problem was formulated as a multi-objective possibilistic mixed integer linear programming model considering the imprecise nature of market demands, cost/time coefficients and capacity levels. Peidro et al. (2009) proposed a fuzzy mono-objective mixed-integer linear programming model for a supply chain tactical planning in which the total cost was to be minimized. Zarandi et al. (2011) used interactive fuzzy goal programming in order to solve the network design problem of a closed-loop supply chain. Liu and Papageorgiou (2013) addressed production, distribution and capacity planning of global supply chains by developing a multi-objective mixed-integer linear programming approach considering total cost, total flow time and total lost sales as three objectives. Özceylan et al. (2013) employed a fuzzy multi-objective linear programming method to solve fuzzy bi-objective reverse logistics network design problems. Two objectives were considered including minimization of the total cost and total delivery time of the system simultaneously. Özceylan et al. (2014) investigated strategic and tactical decisions problems for a closed-loop supply chain (CLSC) network model consisting of various conflicting decisions of forward and reverse facilities. To this aim, a fuzzy multi-objective mixed-integer non-linear programming model was proposed. 
In recent years, supply chains design concerned with environmental issues has been increasingly investigated through several research works. Paksoy et al. (2012) provided a fuzzy multi-objective model to design a green closed-loop supply chain network. The objectives are to minimize all the transportation costs for the supply chain's forward and reverse logistics, minimize total $\mathrm{CO} 2$ emissions and to encourage customers to use recyclable materials as an environmental practice. Pishvaee and Razmi (2012) proposed a multi-objective fuzzy mathematical programming model for designing a supply chain network towards the optimization of two objectives which are minimization of the total cost and the environmental impact. Kannan et al. (2013) proposed an approach to rank and select the best green suppliers of a supply chain according to economic and environmental criteria and then allocating the optimum order quantities among them. The proposed approach was a combination of the fuzzy multi-attribute utility theory and multi-objective programming. Harris et al. (2014) proposed a multi-objective optimization approach for solving a facility location-allocation problem for a supply chain network where financial costs and $\mathrm{CO}_{2}$ emissions are considered as objectives. Talaei et al. (2015) presented a bi-objective facility location-allocation model for a closed loop supply chain network design. Robust and fuzzy programming approaches were used to investigate the effects of uncertainties of the variable costs, as well as the demand rate on the network design.

Based on the aforementioned literature review, a large and growing body of research works has investigated FSCND problems focusing on one or multiple objectives, but not all the objectives together that we consider in this article; which considers four of the main key factors for a successful FSC. These factors are (i) the total transportation and implementation cost (ii) the impact on environment (iii) the average delivery rate in satisfying product quantity as requested by abattoirs and retailers and (iv) the distribution time of products which is a key for food quality. Furthermore, few or no empirical research has taken into account the additional 
cost required for implementing a new technology (e.g. RFID) into the FSCs which aims at maintaining food safety throughout the SCN.

In spite of the reviewed literature showed that several research works have applied the fuzzy optimization approach in supply chains network design, to the best of our knowledge, limited or no study applied the fuzzy optimization approach in the context of green FSCs considering

(i) multiple uncertainties in the input data such as costs, demand and capacity levels and (ii) strategic and tactical design decisions. Furthermore, no empirical study examined the impact (in costs) of the RFID implementation on FSCs.

The main contributions of this article can be summarized as follows:

- It presents a development of a fuzzy multi-objective programming model of a threeechelon green meat supply chain. The model can be used as a product distribution planner in supporting strategic and tactical design decisions.

- It considers the optimization of four of the main key factors for a successful FSC including minimization of total transportation and implementation cost, minimization of environmental impact ( $\mathrm{CO}_{2}$ emission), maximization of average delivery rate and minimization of distribution time of products which is a key factor for food quality.

- To come closer to reality, the developed model also incorporates the consideration of uncertainty of input data in transportation and implementation costs, demand in quantity of products requested by abattoirs and retailers and capacity levels of related facilities.

- It presents a cost-effective analysis for the impact (in costs) of the RFID implementation on a MSC. The non-RFID-based MSC network was formulated as a mono-objective model aims at minimizing the total transportation and implementation cost. It can be a useful tool for decision makers to determine a cost-effective analysis of RFID-based FSC networks. 
- Different solution methods that transform the fuzzy multi-objective model into a fuzzy mono-objective model were investigated. Subsequently, the performances of these abattoirs and retailers.

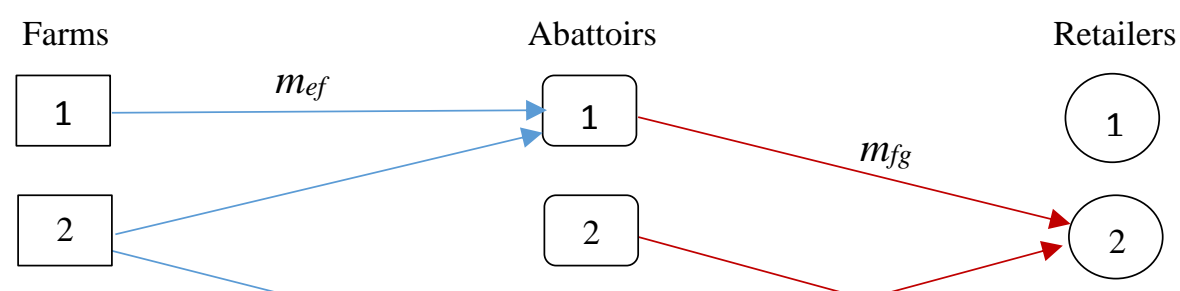


Fig.1 The three-echelon meat supply chain network.

The FMOPM model for the MSC problems is formulated based on the following basic assumptions:

- Critical parameters such as transportation and implementation costs, demand and capacity levels are assumed to be uncertain.

- The MSC under investigation is a forward SC network.

- The potential location of farms and abattoirs are known.

- The number of retailers is fixed.

- $\mathrm{CO}_{2}$ emission/vehicle/m is assumed certain.

- There is no product transportation between facilities at the same level i.e., between two farms.

- There is no consideration for different meat types.

217 The following sets, parameters and decision variables were used for formulating the FMOPM:

218 Sets

219

$E$ set of farms $(1 \ldots e \ldots E)$

220

$F$ set abattoirs $(1 \ldots f \ldots F)$ 
$G$ set retailers $(1 \ldots \mathrm{g} \ldots \mathrm{G})$

222

223 Parameters

$224 C_{e f}^{t} \quad$ RFID tag cost (GBP) per item transported from farm $e$ to abattoir $f$

$225 C_{f g}^{t} \quad$ RFID tag cost (GBP) per item transported from abattoir $f$ to retailer $g$

$226 C_{e f}^{m / l} \quad$ RFID system cost (GBP) required per lorry $l$ travelling from farm $i$ to abattoir $j$

$227 C_{f g}^{m / l} \quad$ RFID system cost (GBP) required per lorry $l$ travelling from abattoir $f$ to retailer $g$

$228 R_{e} \quad$ working rate (items) per labourer at farm $e$

$229 R_{f} \quad$ working rate (items) per labourer at abattoir $f$

$230 N_{e}$ minimum required number of working hours for labourer at farm $e$

$231 N_{f}$ minimum required number of working hours for labourer at abattoir $f$

$232 T C_{e f}$ unit transportation cost (GBP) per mile from farm $e$ to abattoir $f$

$233 T C_{f g}$ unit transportation cost (GBP) per mile from abattoir $f$ to retailer $g$

$234 C_{e}^{h}$ handling cost per livestock at farms $e$

$235 C_{f}^{h}$ handling cost per meat piece at abattoir $f$

$236 d_{e f} \quad$ transportation distance (mile) of livestock from farm $e \mathrm{t}$ abattoir $f$

$237 d_{f g} \quad$ transportation distance (mile) of processed meats from abattoir $f$ to retailer $g$

$238 C_{l} \quad$ transportation capacity (units) per lorry $l$

$239 V_{l} \quad$ velocity $(\mathrm{m} / \mathrm{h})$ of lorry $l$

240

$241 C_{e}$ maximum supply capacity (units) of farm $e$

$242 \quad C_{f} \quad$ maximum supply capacity (units) of abattoir $f$ 
$\mathrm{D}_{f} \quad$ minimum demand (in units) of abattoir $f$

$244 \quad \mathrm{D}_{g} \quad$ minimum demand (in units) of retailer $g$

$245 \mathrm{CO}_{2 e} \mathrm{CO}_{2}$ emission in gram for opening farm $e$

$246 \mathrm{CO}_{2 f} \mathrm{CO}_{2}$ emission in gram for opening abattoir $f$

$247 \mathrm{CO}_{2 e f} \mathrm{CO}_{2}$ emission in gram per mile for each vehicle travelling from farm $e$ to abattoir $f$

$248 \mathrm{CO}_{2 f g} \mathrm{CO}_{2}$ emission in gram per mile for vehicle travelling from abattoir $f$ to retailer $g$

249

250 Decision variables

$251 m_{e f}$ quantity of livestock transported from farm $e$ to abattoir $f$

$252 m_{f g}$ quantity of processed meats transported from abattoir $f$ to retailer $g$

$253 x_{e}$ number of required labourers at farm $e$

254

$x_{f} \quad$ number of required labourers at abattoir $f$

255

256 Binary decision variables:

257

258

$u_{e}=\{1:$ if farm $e$ is open

259

260

$v_{f}=\left\{\begin{array}{l}1: \text { if abattoir } f \text { is open } \\ 0: \text { otherwise }\end{array}\right.$

261 Four conflicting objectives, which include minimizing the total transportation and 262 implementation cost $\left(\mathrm{Z}_{1}\right)$, minimizing the environmental impact $\left(\mathrm{Z}_{2}\right)$, maximizing the average delivery rate $\left(Z_{3}\right)$ and minimizing the distribution time $\left(Z_{4}\right)$, can be defined as objective functions below: 


$$
\begin{aligned}
& \operatorname{Min} Z_{1}=\sum_{e \in E} \sum_{f \in F} T C_{e f}\left\lceil\frac{m_{e f}}{W_{l}}\right\rceil d_{e f}+\sum_{f \in F} \sum_{g \in G} T C_{f g}\left\lceil\frac{m_{f g}}{W_{l}}\right\rceil d_{f g} \\
& +\sum_{e \in E} \sum_{f \in F} C_{e}^{d} m_{e f}+\sum_{f \in F} \sum_{g \in G} C_{f}^{d} m_{f g}+\sum_{e \in E} \sum_{f \in F} C_{e f}^{t} m_{e f}+\sum_{f \in F} \sum_{g \in G} C_{f g}^{t} m_{f g} \\
& +\sum_{e \in E} \sum_{f \in F} C_{e f}^{m / l}\left\lceil\frac{m_{e f}}{W_{l}}\right\rceil+\sum_{f \in F} \sum_{g \in G} C_{f g}^{m / l}\left\lceil\frac{m_{f g}}{W_{l}}\right\rceil-\sum_{e \in E} L_{e} x_{e} N_{e}-\sum_{f \in F} L_{f} x_{f} N_{f}
\end{aligned}
$$

$\operatorname{Min} Z_{2}=\sum_{e \in E} C O_{2 e} u_{e}+\sum_{f \in F} C O_{2 f} v_{f}+\sum_{e \in E} \sum_{f \in F} C O_{2 e f}\left\lceil\frac{m_{e f}}{W_{l}}\right\rceil d_{e f}+\sum_{f \in F} \sum_{g \in G} C O_{2 f g}\left\lceil\frac{m_{f g}}{W_{l}}\right\rceil d_{f g}$

$\operatorname{Max} Z_{3}=\frac{\sum_{f \in F}\left(\sum_{e \in E} m_{e f} / D_{f}\right)+\sum_{g \in G}\left(\sum_{f \in F} m_{f g} / D_{g}\right)}{2}$

$\operatorname{Min} Z_{4}=\sum_{e \in E} \sum_{f \in F} \frac{d_{e f}}{V_{l}} m_{e f}+\sum_{f \in F} \sum_{g \in G} \frac{d_{f g}}{V_{l}} m_{f g}$

By minimizing the total transportation and implementation cost based on the non RFID-based MSC model ( $\left.Z^{n o n}\right)$, it is given as follows:

$$
\begin{aligned}
& \text { Min } Z^{n o n}=\sum_{e \in E} \sum_{f \in F} T C_{e f}\left\lceil\frac{m_{e f}}{W_{l}}\right\rceil d_{e f}+\sum_{f \in F} \sum_{g \in G} T C_{f g}\left\lceil\frac{m_{f g}}{W_{l}}\right\rceil d_{f g} \\
& +\sum_{e \in E} \sum_{f \in F} C_{e}^{d} m_{e f}+\sum_{f \in F} \sum_{g \in G} C_{f}^{d} m_{f g}+\sum_{e \in E} L_{e} x_{e} N_{e}+\sum_{f \in F} L_{f} x_{f} N_{f}
\end{aligned}
$$

Subject to:

$\sum_{e \in E} m_{e f} \leq C_{e} \mathrm{u}_{e} \quad \forall \mathrm{f} \in F$ 


$$
\begin{array}{ll}
\sum_{f \in F} m_{f g} \leq C_{f} \mathrm{v}_{f} & \forall \mathrm{g} \in G \\
\sum_{e \in E} m_{e f} \geq \mathrm{D}_{f} & \forall \mathrm{f} \in F \\
\sum_{f \in F} m_{f g} \geq \mathrm{D}_{g} & \forall \mathrm{g} \in G \\
\mathrm{D}_{f} \geq \sum_{g \in G} m_{f g} & \forall \mathrm{f} \in F \\
\sum_{f \in F} m_{e f} \leq x_{e} \mathrm{R}_{e} & \forall \mathrm{e} \in E \\
\sum_{g \in G} m_{f g} \leq x_{f} \mathrm{R}_{f} & \forall \mathrm{f} \in F \\
m_{e f}, m_{f g} \geq 0 & \forall e, f, g \\
u_{e}, v_{f} \in\{1,0\}, & \forall e, f
\end{array}
$$

Where, for Eq. (1) it minimizes the total transportation and implementation cost which includes transportation cost in the meat supply network, handling cost at farms and abattoirs, RFID-tag cost for each item, RFID reader cost required for each transportation vehicle and labour costs saved after the RFID implementation due to the elimination of several manual operations (e.g. inventory cost). For Eq. (2) it minimizes the amount of $\mathrm{CO}_{2}$ emissions (i) as a result of opening network related facilities (e.g. farms and abattoirs) and (ii) throughout the two-level transportation routes from farms to abattoirs and from abattoirs to retailers. For Eq. (3) it maximizes the average delivery rate in terms of quantity of products requested by abattoirs and retailers. For Eq. (4), it minimizes the distribution time of all products transported from farms to abattoirs and from abattoirs to retailers. For Eq. (5) it determines the minimum total cost for the non-RFID based MSC; the cost includes the transportation cost, labour cost and the material handling cost. For Eq. (6) it limits the amount of livestock shipped from farms to abattoirs so that it cannot exceed the full capacity farms. For Eq. (7) it ensures the flow of meat products from abattoirs to retailer does not exceed the full capacity of abattoirs. For Equations (8-10) 
these maintain the flow of product quantity between the farms and abattoirs and between the

287

288

289

290

291

292

293

294

295

296

297 abattoirs and retailers. For equations (11 and12) they determine the required number of labourers at farms and abattoirs. For equations (13 and14) they limit the non-binary and nonnegativity restrictions on decision variables.

\subsection{Modelling the uncertainty}

In this work, a fuzzy multi-objective programming model was developed to incorporate parameters of the meat supply chain as transportation and implementation costs, demand and capacity levels of related facilities were considered as uncertain parameters. To this aim, the multi-objective programming model was transformed to a crisp model using an approach proposed by Jiménez et al. (2007). Based on Jiménez's approach, the equivalent crisp model is expressed as follows:

$$
\begin{aligned}
& \operatorname{Min} Z_{1}=\sum_{e \in E} \sum_{f \in F}\left(\frac{T C_{e f}^{p e s}+2 T C_{e f}^{\text {mos }}+T C_{e f}^{o p t}}{4}\right)\left\lceil\frac{m_{e f}}{W_{l}}\right\rceil d_{e f}+\sum_{f \in F} \sum_{g \in G}\left(\frac{T C_{f g}^{p e s}+2 T C_{f g}^{\text {mos }}+T C_{f g}^{o p t}}{4}\right)\left\lceil\frac{m_{f g}}{W_{l}}\right\rceil d_{f g} \\
& +\sum_{e \in E} \sum_{F \in f}\left(\frac{C_{e}^{d p e s}+2 C_{e}^{d m o s}+C_{e}^{d o p t}}{4}\right) m_{e f}+\sum_{f \in F} \sum_{g \in G}\left(\frac{C_{f}^{d p e s}+2 C_{f}^{d m o s}+C_{f}^{d o p t}}{4}\right) m_{f g} \\
& +\sum_{e \in E} \sum_{f \in F}\left(\frac{C_{e f}^{\text {tpes }}+2 C_{e f}^{\text {tmos }}+C_{e f}^{\text {topt }}}{4}\right) m_{e f}+\sum_{f \in F} \sum_{g \in G}\left(\frac{C_{f g}^{\text {tpes }}+2 C_{f g}^{\text {tmos }}+C_{f g}^{\text {topt }}}{4}\right) m_{f g} \\
& +\sum_{e \in E} \sum_{f \in F}\left(\frac{C_{e f}^{\frac{m}{l} p e s}+2 C_{e f}^{\frac{m}{l} m o s}+C_{e f}^{\frac{m}{l} o p t}}{4}\right)\left\lceil\frac{m_{e f}}{W_{l}}\right\rceil+\sum_{f \in F} \sum_{g \in G}\left(\frac{C_{f g}^{\frac{m}{l} p e s}+2 C_{f g}^{\frac{m}{l} m o s}+C_{f g}^{\frac{m}{l} o p t}}{4}\right)\left\lceil\frac{m_{f g}}{W_{l}}\right\rceil \\
& -\sum_{e \in E}\left(\frac{L_{e}^{p e s}+2 L_{e}^{m o s}+L_{e}^{o p t}}{4}\right) x_{e} N_{e}-\sum_{f \in F}\left(\frac{L_{f}^{p e s}+2 L_{f}^{m o s}+L_{f}^{o p t}}{4}\right) x_{f} N_{f}
\end{aligned}
$$

$\operatorname{Min} Z_{2}=\sum_{e \in E} C O_{2 e} u_{e}+\sum_{f \in F} C O_{2 f} v_{f}+\sum_{e \in E} \sum_{f \in F} C O_{2 e f}\left\lceil\frac{m_{e f}}{W_{l}}\right\rceil d_{e f}+\sum_{f \in F} \sum_{g \in G} C O_{2 f g}\left\lceil\frac{m_{f g}}{W_{l}}\right\rceil d_{f g}$ 
$\operatorname{Max}_{3}=\frac{\sum_{f \in F}\left(\sum^{e \in E} m_{e f} / D_{f}^{p e s}+2 D_{f}^{m o s}+D_{f}^{o p t}\right)+\sum_{g \in G}\left(4^{\sum_{f \in F} m_{f g}} / D_{g}^{p e s}+2 D_{g}^{m o s}+D_{g}^{o p t}\right)}{2}$

$\operatorname{Min} Z_{4}=\sum_{e \in E} \sum_{f \in F} \frac{d_{e f}}{V_{l}} m_{e f}+\sum_{f \in F} \sum_{g \in G} \frac{d_{f g}}{V_{l}} m_{f g}$

298

299 Subject to:

$\sum_{e \in E} m_{e f} \leq\left[\frac{\alpha}{2} \cdot \frac{C_{e 1}+C_{e 2}}{2}+\left(1-\frac{\alpha}{2}\right) \frac{C_{e 3}+C_{e 4}}{2}\right] \mathrm{u}_{e}, \quad \forall \mathrm{f} \in F$

$\sum_{f \in F} m_{e f} \leq\left[\frac{\alpha}{2} \cdot \frac{C_{f 1}+C_{f 2}}{2}+\left(1-\frac{\alpha}{2}\right) \frac{C_{f 3}+C_{f 4}}{2}\right] \mathrm{v}_{f}, \quad \forall \mathrm{g} \in G$

$\sum_{e \in E} m_{e f} \geq\left[\frac{\alpha}{2} \cdot \frac{\mathrm{D}_{f 1}+\mathrm{D}_{f 2}}{2}+\left(1-\frac{\alpha}{2}\right) \frac{\mathrm{D}_{f 3}+\mathrm{D}_{f 4}}{2}\right], \quad \forall \mathrm{f} \in F$

$\sum_{f \in F} m_{f g} \geq\left[\frac{\alpha}{2} \cdot \frac{\mathrm{D}_{g 1}+\mathrm{D}_{g 2}}{2}+\left(1-\frac{\alpha}{2}\right) \frac{\mathrm{D}_{g 3}+\mathrm{D}_{g 4}}{2}\right], \quad \forall \mathrm{g} \in G$

$\left[\frac{\alpha}{2} \cdot \frac{\mathrm{D}_{f 1}+\mathrm{D}_{f 2}}{2}+\left(1-\frac{\alpha}{2}\right) \frac{\mathrm{D}_{f 3}+\mathrm{D}_{f 4}}{2}\right] \geq \sum_{g \in G} m_{f g}, \quad \forall \mathrm{f} \in F$

$\sum_{f \in F} m_{e f} \leq x_{e} \mathrm{R}_{e} \quad \forall \mathrm{e} \in E$

$\sum_{g \in G} m_{f g} \leq x_{f} \mathrm{R}_{f} \quad \forall \mathrm{f} \in F$

$m_{e f}, m_{f g} \geq 0 \quad \forall e, f$

$u_{e}, v_{f}, \alpha \in\{1,0\}, \quad \forall e, f$ 
301 According to Jiménez's approach, it is supposed that the fuzzy constraints in the model should 302 be satisfied with a confidence value which is denoted as $\alpha$ and it is normally determined by 303 decision makers.

\section{Optimization strategy}

The developed FMOPM was proposed to be optimized using the flowing steps:

Step 1 : Determine a maximum bound and a minimum bound (Max, Min) for each objective function as follows:

For the Max bound solution:

$$
\begin{aligned}
& \operatorname{Max} \mathrm{Z}_{1}\left(\operatorname{Max}_{1}\right)=\sum_{e \in E} \sum_{f \in F} T C_{e f}\left\lceil\frac{m_{e f}}{W_{l}}\right\rceil d_{e f}+\sum_{f \in F} \sum_{g \in G} T C_{f g}\left\lceil\frac{m_{f g}}{W_{l}}\right\rceil d_{f g} \\
& +\sum_{e \in E} \sum_{f \in F} C_{e}^{d} m_{e f}+\sum_{f \in F} \sum_{g \in G} C_{f}^{d} m_{f g}+\sum_{e \in E} \sum_{f \in F} C_{e f}^{t} m_{e f}+\sum_{f \in F} \sum_{g \in G} C_{f g}^{t} m_{f g} \\
& +\sum_{e \in E} \sum_{f \in F} C_{e f}^{m / l}\left\lceil\frac{m_{e f}}{W_{l}}\right\rceil+\sum_{f \in F} \sum_{g \in G} C_{f g}^{m / l}\left\lceil\frac{m_{f g}}{W_{l}}\right\rceil-\sum_{e \in E} L_{e} x_{e} N_{e}-\sum_{f \in F} L_{f} x_{f} N_{f}
\end{aligned}
$$

$$
\begin{aligned}
& \operatorname{Max} Z_{2}\left(\operatorname{Max}_{2}\right)=\sum_{e \in E} C O_{2 e} u_{e}+\sum_{f \in F} C O_{2 f} v_{f} \\
& +\sum_{e \in E} \sum_{f \in F} C O_{2 e f}\left\lceil\frac{m_{e f}}{W_{l}}\right\rceil d_{e f}+\sum_{f \in F} \sum_{g \in G} C O_{2 f g}\left\lceil\frac{m_{f g}}{W_{l}}\right\rceil d_{f g}
\end{aligned}
$$$$
\operatorname{Max}_{3}\left(\operatorname{Max}_{3}\right)=\frac{\sum_{f \in F}\left(\sum_{e \in E} m_{e f} / D_{f}\right)+\sum_{g \in G}\left(\sum_{f \in F} m_{f g} / D_{g}\right)}{2}
$$

$$
\operatorname{Max} Z_{4}\left(\operatorname{Max}_{4}\right)=\sum_{e \in E} \sum_{f \in F} \frac{d_{e f}}{V_{l}} m_{e f}+\sum_{f \in F} \sum_{g \in G} \frac{d_{f g}}{V_{l}} m_{f g}
$$

For the Min bound solution: 
$\operatorname{Min} \mathrm{Z}_{1}\left(\operatorname{Min}_{1}\right)=\sum_{e \in E} \sum_{f \in F} T C_{e f}\left\lceil\frac{m_{e f}}{W_{l}}\right\rceil d_{e f}+\sum_{f \in F} \sum_{g \in G} T C_{f g}\left\lceil\frac{m_{f g}}{W_{l}}\right\rceil d_{f g}$

$+\sum_{e \in E} \sum_{f \in F} C_{e}^{d} m_{e f}+\sum_{f \in F} \sum_{g \in G} C_{f}^{d} m_{f g}+\sum_{e \in E} \sum_{f \in F} C_{e f}^{t} m_{e f}+\sum_{f \in F} \sum_{g \in G} C_{f g}^{t} m_{f g}$

$+\sum_{e \in E} \sum_{f \in F} C_{e f}^{m / l}\left\lceil\frac{m_{e f}}{W_{l}}\right\rceil+\sum_{f \in F} \sum_{g \in G} C_{f g}^{m / l}\left\lceil\frac{m_{f g}}{W_{l}}\right\rceil-\sum_{e \in E} L_{e} x_{e} N_{e}-\sum_{f \in F} L_{f} x_{f} N_{f}$

$\operatorname{Min} Z_{2}\left(\operatorname{Min}_{2}\right)=\sum_{e \in E} C O_{2 e} u_{e}+\sum_{f \in F} C O_{2 f} v_{f}$

$+\sum_{e \in E} \sum_{f \in F} C O_{2 e f}\left\lceil\frac{m_{e f}}{W_{l}}\right\rceil d_{e f}+\sum_{f \in F} \sum_{g \in G} C O_{2 f g}\left\lceil\frac{m_{f g}}{W_{l}}\right\rceil d_{f g}$

$\operatorname{Min} Z_{3}\left(\operatorname{Min}_{3}\right)=\frac{\sum_{f \in F}\left(\sum_{e \in E} m_{e f} / D_{f}\right)+\sum_{g \in G}\left(\sum_{f \in F} m_{f g} / D_{g}\right)}{2}$

$\operatorname{Min} Z_{4}\left(\operatorname{Min}_{4}\right)=\sum_{e \in E} \sum_{f \in F} \frac{d_{e f}}{V_{l}} m_{e f}+\sum_{f \in F} \sum_{g \in G} \frac{d_{f g}}{V_{l}} m_{f g}$

Step 2 : Each objective function corresponds to an equivalent linear membership function, which can be obtained by implementing Eq. (36-39). Further illustration about these membership functions is depicted in Fig. 2.

$$
\begin{aligned}
& \mu_{1}\left(Z_{1}(x)\right)= \begin{cases}1 & \text { if } \mathrm{Z}_{1}(x) \leq \operatorname{Max}_{1} \\
\frac{\operatorname{Min}_{1}-Z_{1}(x)}{\operatorname{Min}_{1}-\operatorname{Max}_{1}} & \text { if } \operatorname{Min}_{1} \leq Z_{1}(x) \leq \operatorname{Max}_{1} \\
0 & \text { if } \mathrm{Z}_{1}(x) \geq \operatorname{Min}_{1}\end{cases} \\
& \mu_{2}\left(Z_{2}(x)\right)= \begin{cases}1 & \text { if } \mathrm{Z}_{2}(x) \leq \operatorname{Max}_{2} \\
\frac{\operatorname{Min}_{2}-Z_{2}(x)}{\operatorname{Min}_{2}-\operatorname{Max}_{2}} & \text { if } \operatorname{Min}_{2} \leq Z_{2}(x) \leq \operatorname{Max}_{2} \\
0 & \text { if } \mathrm{Z}_{2}(x) \geq \operatorname{Min}_{2}\end{cases}
\end{aligned}
$$




$$
\begin{aligned}
& \mu_{3}\left(Z_{3}(x)\right)= \begin{cases}1 & \text { if } \mathrm{Z}_{2}(x) \leq \operatorname{Max}_{2} \\
\frac{\operatorname{Min}_{2}-Z_{2}(x)}{\operatorname{Min}_{2}-\operatorname{Max}_{2}} & \text { if } \operatorname{Min}_{2} \leq Z_{2}(x) \leq \operatorname{Max}_{2} \\
0 & \text { if } \mathrm{Z}_{2}(x) \geq \operatorname{Min}_{2}\end{cases} \\
& \mu_{4}\left(Z_{4}(x)\right)= \begin{cases}1 & \text { if } \mathrm{Z}_{4}(x) \leq \operatorname{Max}_{4} \\
\frac{\operatorname{Min}_{4}-Z_{4}(x)}{\operatorname{Min}_{4}-\operatorname{Max}_{4}} & \text { if } \operatorname{Min}_{4} \leq Z_{4}(x) \leq \operatorname{Max}_{4} \\
0 & \text { if } \mathrm{Z}_{4}(x) \geq \operatorname{Min}_{4}\end{cases}
\end{aligned}
$$

313 where Eq. (35-37) indicates the satisfaction degree of the three objective functions respectively.

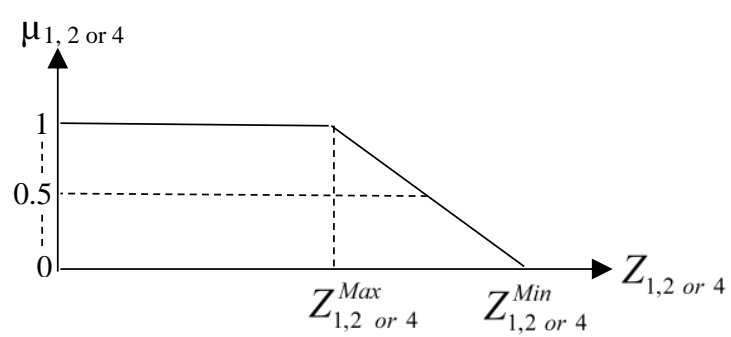

(a) $\mathrm{Z}_{1}, \mathrm{Z}_{2}$ and $\mathrm{Z}_{4}$

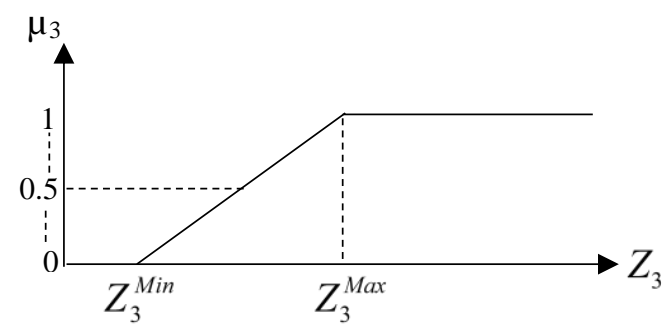

(b) $\mathrm{Z}_{3}$

319 Fig. 2. Membership functions related to the four objectives (a) $\mathrm{Z}_{1}, \mathrm{Z}_{2}$ and $\mathrm{Z}_{4}$, (b) $\mathrm{Z}_{3}$.

Step 3 : Solve the crisp FMOPM obtained from section 3.1 by transforming it to a monoobjective model using the proposed solution methods described in section 4.1.

Step 4 : Use the Max-Min method (described in section 4.2) to select the best Pareto solution. 
326 In the LP-metrics method, each objective function needs to be optimized individually. This 327 aims at obtaining the ideal objective values $\left(Z_{1}^{*}, Z_{2}^{*}, Z_{3}^{*}\right.$ and $\left.Z_{4}^{*}\right)$. The FMOPM is optimized as a 328 single objective model using the following formula (Al-e-hashem et al., 2011):

329

$$
\operatorname{Min} \mathrm{Z}=\left[w_{1} \frac{Z_{1}-Z_{1}^{*}}{Z_{1}^{*}}+w_{2} \frac{Z_{2}-Z_{2}^{*}}{Z_{2}^{*}}+w_{3} \frac{Z_{3}-Z_{3}^{*}}{Z_{3}^{*}}+w_{4} \frac{Z_{4}-Z_{4}^{*}}{Z_{4}^{*}}\right]
$$

330

331 Subject to Eq. (19-27).

332

4.1.2 $\varepsilon$-constraint

In the $\varepsilon$-constraint method, the FMOPM turns into a single-objective model by keeping the 335 most important function as an objective function, and considering other functions as the $\varepsilon$ based constraints (Ehrgott, 2005). Thus, the equivalent solution formula (Z) is given by:

337

$\operatorname{Min} Z=\operatorname{Min} Z_{1}$

338 Subject to:

339

$$
\begin{aligned}
& Z_{2} \leq \varepsilon_{1} \\
& {\left[Z_{2}\right]^{\text {min }} \leq \varepsilon_{1} \leq\left[Z_{2}\right]^{\text {max }}} \\
& Z_{3} \geq \varepsilon_{2} \\
& {\left[Z_{3}\right]^{\text {min }} \leq \varepsilon_{2} \leq\left[Z_{3}\right]^{\text {max }}} \\
& Z_{4} \leq \varepsilon_{4} \\
& {\left[Z_{4}\right]^{\text {min }} \leq \varepsilon_{3} \leq\left[Z_{4}\right]^{\max }}
\end{aligned}
$$


341 And Eq. (19-27).

342 In this work, minimization of the total transportation and implementation cost is the objective

343 function as Eq.39 and minimization of $\mathrm{CO}_{2}$ emissions, maximization of average delivery rate

344 and minimization of distribution time are shifted to constraints (Eq.40, 42 and 44 respectively).

$345 \quad$ 4.1.3 Goal programming

346 The purpose of Goal programming is to find a solution that minimizes undesirable deviations

347 between the objective functions and their corresponding goals (Pasandideh et al., 2015).

348 Equations 36-39 show the used solution functions for this problem.

Min Z

$\frac{\varsigma^{1}}{\mathrm{G}^{1}} \leq Z$

$\frac{v^{2}}{G^{2}} \leq Z$

$\frac{v^{3}}{G^{3}} \leq Z$

$\frac{v^{4}}{G^{4}} \leq Z$

349 The equivalent objective functions are expressed as follows. 


$$
\begin{aligned}
& \operatorname{Min} Z_{1}=\sum_{e \in E} \sum_{f \in F} T C_{e f}\left\lceil\frac{m_{e f}}{W_{l}}\right\rceil d_{e f}+\sum_{f \in F} \sum_{g \in G} T C_{f g}\left\lceil\frac{m_{f g}}{W_{l}}\right\rceil d_{f g} \\
& +\sum_{e \in E} \sum_{f \in F} C_{e}^{d} m_{e f}+\sum_{f \in F} \sum_{g \in G} C_{f}^{d} m_{f g}+\sum_{e \in E} \sum_{f \in F} C_{e f}^{t} m_{e f}+\sum_{f \in F} \sum_{g \in G} C_{f g}^{t} m_{f g} \\
& +\sum_{e \in E} \sum_{f \in F} C_{e f}^{m / l}\left\lceil\frac{m_{e f}}{W_{l}}\right\rceil+\sum_{f \in F} \sum_{g \in G} C_{f g}^{m / l}\left\lceil\frac{m_{f g}}{W_{l}}\right\rceil-\sum_{e \in E} L_{e} x_{e} N_{e}-\sum_{f \in F} L_{f} x_{f} N_{f}+\varsigma^{1}-v^{1}=\mathrm{G}^{1}
\end{aligned}
$$

$\operatorname{Min} Z_{2}=\sum_{e \in E} C O_{2 e} u_{e}+\sum_{f \in F} C O_{2 f} v_{f}$

$+\sum_{e \in E} \sum_{f \in F} C O_{2 e f}\left\lceil\frac{m_{e f}}{W_{l}}\right\rceil d_{e f}+\sum_{f \in F} \sum_{g \in G} C O_{2 f g}\left\lceil\frac{m_{f g}}{W_{l}}\right\rceil d_{f g}+\varsigma^{2}-v^{2}=\mathrm{G}^{2}$

$\operatorname{Max} Z_{3}=\frac{\sum_{f \in F}\left(\sum_{e \in E} m_{e f} / D_{f}\right)+\sum_{g \in G}\left(\sum_{f \in F} m_{f g} / D_{g}\right)}{2}+\varsigma^{3}-v^{3}=\mathrm{G}^{3}$

$\operatorname{Min} Z_{4}=\sum_{e \in E} \sum_{f \in F} \frac{d_{e f}}{V_{l}} m_{e f}+\sum_{f \in F} \sum_{g \in G} \frac{d_{f g}}{V_{l}} m_{f g}+\varsigma^{4}-v^{4}=\mathrm{G}^{4}$

Where

$\mathrm{G}^{1} \quad$ goal of the objective 1

$\mathrm{G}^{2} \quad$ goal of the objective 2

$\mathrm{G}^{3} \quad$ goal of the objective 3

$\mathrm{G}^{4} \quad$ goal of the objective 4

$\varsigma^{1} \quad$ negative deviation variable of the objective 1

$\varsigma^{2} \quad$ negative deviation variable of the objective 2

$\varsigma^{3} \quad$ negative deviation variable of the objective 3

$\varsigma^{4} \quad$ negative deviation variable of the objective 4

$v^{1} \quad$ positive deviation variable of the objective 1 

$v^{2}$
positive deviation variable of the objective 2
$v^{3}$
positive deviation variable of the objective 3
$v^{4}$
positive deviation variable of the objective 4

351 Subject to the additional non-negativity restriction where:

$$
\varsigma, v \geq 0 \text {, }
$$

352 And Eq. (18-26).

353

\subsection{The Max-Min}

354 In this work, the Max-Min method was used to select the best trade-off solution. Accordingly,

355 the selection formula is expressed as follows:

$$
B T=\sum_{i=1}^{4} \frac{Z_{i}}{Z_{i}^{*}}
$$

356 Fig. 3. shows the procedures for developing and optimizing the fuzzy multi-objective

357 distribution planner.

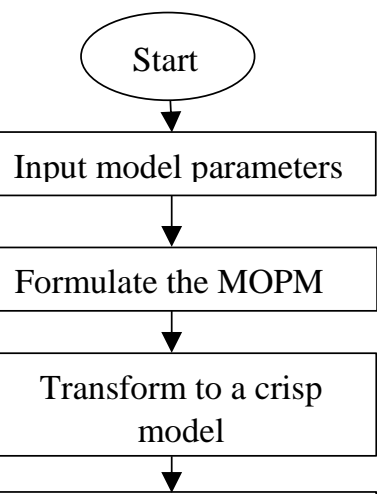

Find the Max and Min solutions for each objective

alculate membership functions for $Z_{1}, Z_{2}, Z_{3}$ and $\mathrm{Z}_{4}$

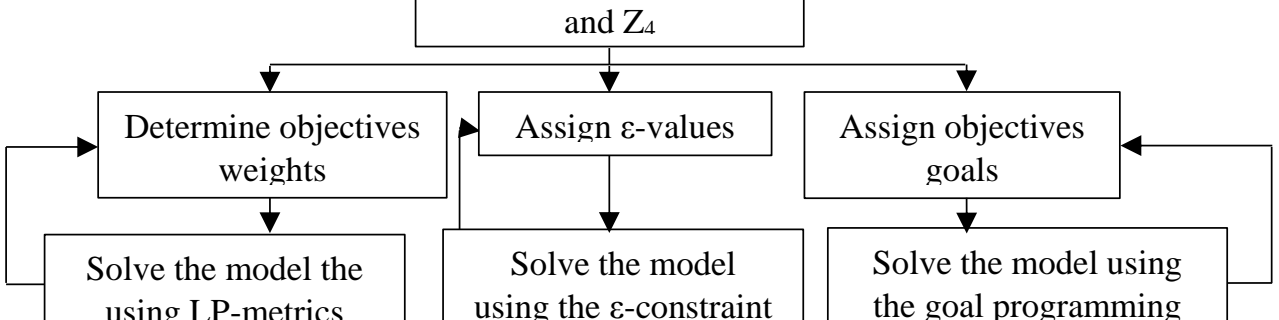


373 Fig. 3. Procedures for developing and optimizing the FMOPM.

\section{Implementation and evaluation of the FMOPM}

375 In this section, a case study was used for evaluating the applicability of the developed FMOPM and the performance of the proposed solution methods. Table 1 shows the relevant parameters and their values used for the case study. Data, which are related to locations of farms, abattoirs and retailers, were collected from the Meat Committee in the UK (HMC, 2015) and Google Map was used to estimate travelling distances in locations between farms, abattoirs and 380 retailers in the South-West of London. The developed model was coded using the LINGO ${ }^{11}$ 381 optimization software to obtain the solution based on the developed FMOPM.

382 Table 1. The values of parameters.

\begin{tabular}{llll}
\hline Parameters & Values & Parameters & values \\
\hline$T C_{e f}$ & $(15,18)$ & $D_{g}$ & $(1400,1500)$ \\
$T C_{f g}$ & $(15,18)$ & $C_{e}$ & $(1500,1800)$ \\
$C_{e f}^{t}$ & $(0.15,0.18)$ & $C_{f}$ & $(1700,2000)$ \\
$L_{e}$ & $(6.5,8.5)$ & $L_{f}$ & $(8.5,10.5)$
\end{tabular}




\begin{tabular}{llll}
\hline$C_{f g}^{t}$ & $(0.15,0.18)$ & $C_{l}$ & $(20,31)$ \\
$C_{e f}^{m / l}$ & $(800,950)$ & $d_{e f}$ & $(43,210)$ \\
$C_{f}^{m / l}$ & $(800,950)$ & $d_{f g}$ & $(110,174)$ \\
$C_{e}^{d}$ & $(3.5,4)$ & $C_{2 e f}$ & $(271,294)$ \\
$C_{f}^{d}$ & $(3.5,4)$ & $C O_{2 f g}$ & $(271,294)$ \\
$D_{f}$ & $(2200,3000)$ & $V_{L}$ & $(90-110)$ \\
$R_{e}$ & $(50,65)$ & $R_{f}$ & $(50,65)$ \\
$C O_{2 f}$ & $(220000,250000)$ & $C O_{2 e}$ & $(82000,85000)$ \\
$N_{e}$ & $(9,12)$ & $N_{f}$ & $(9,12)$ \\
\hline
\end{tabular}

383

$384 \quad 5.1$ Computational results

385 First, the Max and Min bounds for the four objectives needed to be determined, to this end Eq.

386 (28-35) were applied. Table 2 shows the obtained results related to $Z_{1}, Z_{2}, Z_{3}$ and $Z_{4}$. For 387 instance, $Z_{1}\{\operatorname{Max}, \operatorname{Min}\}=\{195,400,43,540\}$. These values were used to obtain the 388 membership functions for each objective.

390 Table 2. Max and Min values in responding to objective $\mathrm{Z}_{1}, \mathrm{Z}_{2}, \mathrm{Z}_{3}$ and $\mathrm{Z}_{4}$, respectively

\begin{tabular}{ccc}
\hline Objective functions & Max & Min \\
\hline$Z_{1}$ & 195400 & 43540 \\
$Z_{2}$ & 2572500.11 & 739782.55 \\
$Z_{3}$ & 0.98 & 0.76 \\
$Z_{4}$ & 245 & 54.5 \\
\hline
\end{tabular}


To minimize the total transportation and implementation cost, $\mathrm{CO}_{2}$ emissions and distribution time and maximize the average delivery rate, the three methods previously described were implemented as follows:

1. LP-metrics: each objective function was optimized independently under the predefined constraints. The results are reported in Table 3. For instance, it shows optimizing the first objective $\left(Z_{1}\right)$ individually, the values of the objective functions are obtained as $Z_{1}$ $=43540, Z_{2}=769600.22, Z_{3}=0.77$ and $Z_{4}=56$. The possible ideal values for the objective functions are boldfaced in the table: $Z_{1}=43540, Z_{2}=739782.55, Z_{3}=0.98$ and $\mathrm{Z}_{4}=54.5$. Then, the Pareto solutions of the FMOPM were obtained based on the weights of the objective functions (See Table 4). Table 5 shows the varying computation result in response to one of ten different weights for each of the four objectives.

2. $\varepsilon$-constraint: as the maximum value and minimum value for each objective can be obtained by Eq. 27-35, the range between the two values was segmented into ten segments, the grid points ( $\varepsilon$-points) in between were assigned as $\varepsilon$ values (See Table 6) in Eq. 42, 44 and 46. Then, Pareto solutions were obtained by Eq. 41. The total transportation and implementation cost is the objective function which can be minimized while the $\mathrm{CO}_{2}$ emissions, the average delivery rate and the distribution time are considered as constraints. Table 7 shows the computation results of the FMOPM for ten $\varepsilon$-iterations.

3. Goal Programming: each objective can be given a goal value to be approached by minimizing the undesired deviation towards to the goal value to be achieved. To this aim, each objective was solved individually and its value is given as a target for the approaching function. The values of objective functions are presented in Table 8 . 
416 It can be seen that the three methods were applied, respectively with ten $\alpha$ levels $(0.1,0.2$, $417 \quad 0.3,0.4,0.5,0.6,0.7,0.8,0.9$ and1). By setting these ten levels to the $\alpha$, with steps 0.1 and 418 implementing it to the model, ten Pareto solutions were obtained. Therefore, the model $419 \quad$ should be frequently solved for each $\alpha$ level.

420 Table 3. Values of $Z_{1}, Z_{2}, Z_{3}$ and $Z_{4}$ obtained by optimizing them individually.

\begin{tabular}{ccccc}
\hline Objective functions & Min $Z_{1}$ & Min $Z_{2}$ & Max $Z_{3}$ & Min $Z_{4}$ \\
\hline$Z_{1}$ & $\mathbf{4 3 5 4 0}$ & 44670 & 195380 & 464000 \\
$Z_{2}$ & 769600.22 & $\mathbf{7 3 9 7 8 2 . 5 5}$ & 2373200.11 & 769600.22 \\
$Z_{3}$ & 0.77 & 0.76 & $\mathbf{0 . 9 8}$ & 0.76 \\
$Z_{4}$ & 56 & 56 & 213 & $\mathbf{5 4 . 5}$ \\
\hline
\end{tabular}

421

422 Table 4. Weights allocation related to the LP-metrics approach.

\begin{tabular}{cl}
\hline & Assigned Weights \\
\hline$\#$ & $w_{1}, w_{2}, w_{3}, w_{4}$ \\
\hline 1 & $0.9,0.025,0.025,0.05$ \\
2 & $0.8,0.1,0.05,0.05$ \\
3 & $0.7,0.1,0.1,0.1$ \\
4 & $0.64,0.12,0.12,0.12$ \\
5 & $0.6,0.13,0.13,0.14$ \\
6 & $0.5,0.25,0.125,0.125$ \\
7 & $0.4,0.2,0.2,0.2$ \\
8 & $0.34,0.22,0.22,0.22$ \\
9 & $0.3,0.23,0.23,0.24$ \\
10 & $0.22,0.26,0.26,0.26$ \\
\hline
\end{tabular}

423

424 Table 5. Computational results of $\mathrm{Z}_{1}, \mathrm{Z}_{2}, \mathrm{Z}_{3}$ and $\mathrm{Z}_{4}$ obtained by the LP-metrics

\begin{tabular}{lll}
\hline Satisfaction level & Objective function solutions & Facilities open
\end{tabular}

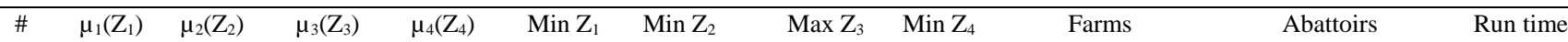
(GBP) $\quad(\mathrm{Kg})$ (\%)

(h)

(s)

0.98

$0.95 \quad 0$.

$0.01 \quad 0.95$

$43540 \quad 741612$

$0.766 \quad 54.5$

(3) Warwick
(5) Leicester

(3) Birmingham

2 
(5) Leicester (4) Balham

(2) Warwick (2) West Midland 3

(3) Warwick (3) Birmingham

(5) Leicester (4) Balham
(2) Warwick
(3) Warwick
(3) Birmingham
(5) Leicester
(5) Norfolk

(2) West Midland 3

(2) Warwick

(1) Warrick

3

(3) Warwick

(3) Birmingham

(5) Leicester

(4) Balham
(2) Warwick
(2) West Midland
(3) Warwick
(3) Birmingham
(5) Leicester
(4) Balham
(5) Norfolk

3
(2) Warwick
(1) Warrick
(3) Warwick
(3) Birmingham
(4)Yorkshire
(4) Balham
(5) Leicester
(5) Norfolk

(1) Yorkshire

(1) Warrick

4

(2) Warwick

(2) West Midland

(3) Warwick

(3) Birmingham

(4)Yorkshire

(4) Balham

(5) Leicester

(5) Norfolk
(1) Yorkshire
(1) Warrick
(2) Warwick
(2) West Midland
(3) Warwick
(3) Birmingham
(4) Yorkshire
(4) Balham
(5) Leicester
(5) Norfolk

4 

(2) Warwick
(2) West Midland
(3) Warwick
(3) Birmingham
(4) Yorkshire
(4) Balham
(5) Leicester
(5) Norfolk

425

426 Table 6. Assignment of $\varepsilon$-value related to the $\varepsilon$-constraint approach

\begin{tabular}{cccc}
\hline \multicolumn{4}{c}{ Assigned $\varepsilon$-value } \\
\hline$\#$ & $\varepsilon_{1}$ & $\varepsilon_{2}$ & $\varepsilon_{3}$ \\
\hline 1 & 743000 & 0.76 & 54.5 \\
2 & 933000 & 0.79 & 60.5 \\
3 & 1123000 & 0.82 & 80.5 \\
4 & 1313000 & 0.85 & 110.5 \\
5 & 1503000 & 0.8 & 130.5 \\
6 & 1693000 & 0.9 & 180.5 \\
7 & 1883000 & 0.91 & 210.5 \\
8 & 2073000 & 0.93 & 220.5 \\
9 & 2263000 & 0.95 & 240.5 \\
10 & 2453000 & 0.97 & 245
\end{tabular}

427

428

429

430

431

432 Table 7. Computational results of $\mathrm{Z}_{1}, \mathrm{Z}_{2}, \mathrm{Z}_{3}$ and $\mathrm{Z}_{4}$ obtained by the $\varepsilon$-constraint

\begin{tabular}{|c|c|c|c|c|c|c|c|c|c|c|c|}
\hline & \multicolumn{4}{|c|}{ Satisfaction level } & \multicolumn{3}{|c|}{ Objective function solutions } & \multicolumn{3}{|c|}{ Facilities open } & \\
\hline \# & $\mu_{1}\left(Z_{1}\right)$ & $\mu_{2}\left(Z_{2}\right)$ & $\mu_{3}\left(Z_{3}\right)$ & $\mu_{4}\left(Z_{4}\right)$ & $\begin{array}{c}\operatorname{Min} Z_{1} \\
(\mathrm{GBP})\end{array}$ & $\begin{array}{l}\operatorname{Min} Z_{2} \\
(\mathrm{Kg})\end{array}$ & $\begin{array}{l}\operatorname{Max} Z_{3} \\
(\%)\end{array}$ & $\begin{array}{l}\operatorname{Min} Z_{4} \\
\text { (h) }\end{array}$ & Farms & Abattoirs & $\begin{array}{c}\text { Run } \\
\text { time } \\
\text { (s) }\end{array}$ \\
\hline 1 & 0.98 & 0.95 & 0.01 & 0.95 & 43540 & 740010 & 0.766 & 54.5 & $\begin{array}{l}\text { (3) Warwick } \\
\text { (5) Leicester }\end{array}$ & $\begin{array}{l}\text { (3) Birmingham } \\
\text { (4) Balham }\end{array}$ & 2 \\
\hline
\end{tabular}




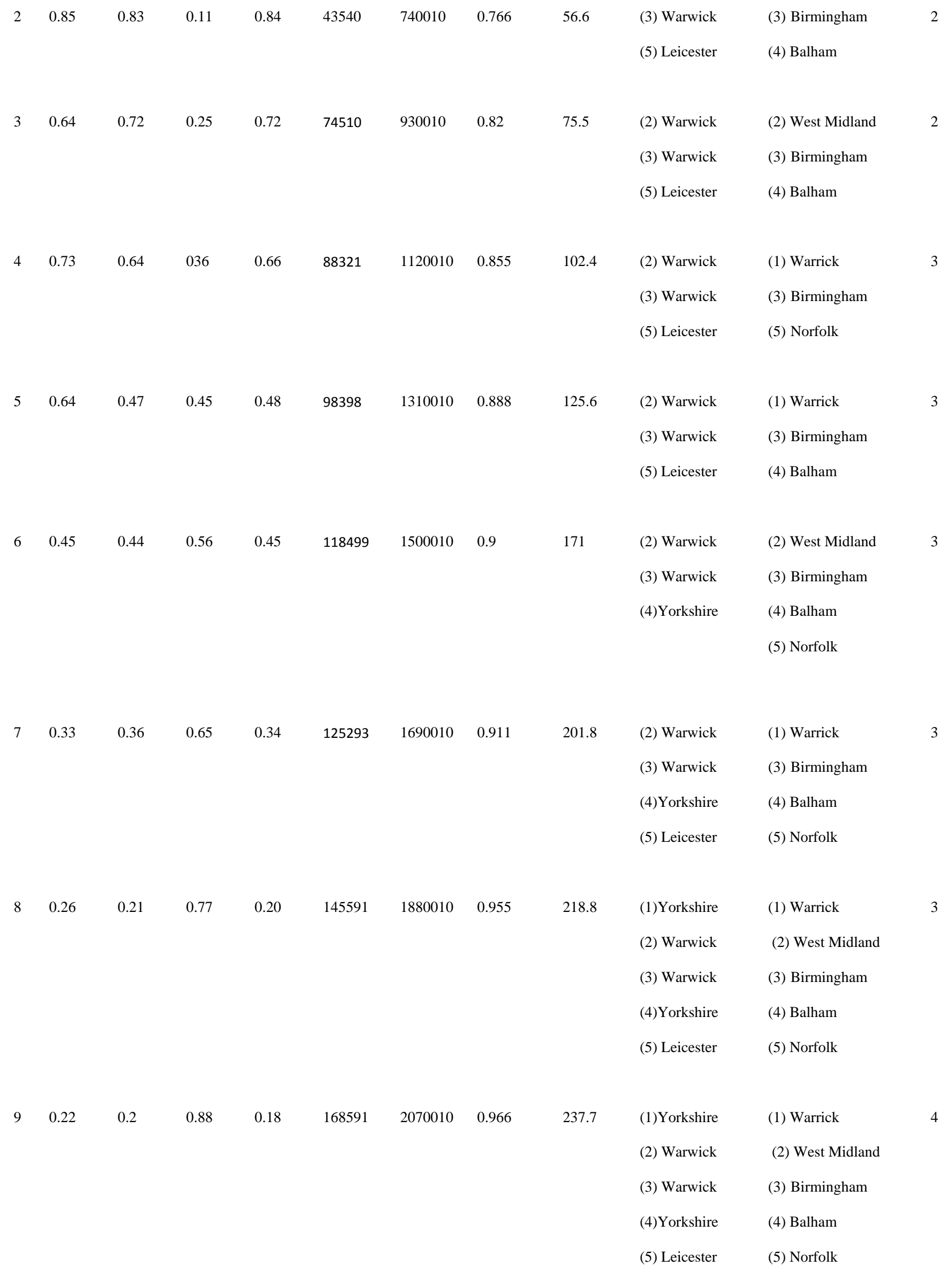


10

$\begin{array}{llllllll}0.09 & 0.1 & 0.98 & 0.09 & 194992 & 2283010 & 0.97 & 244.5\end{array}$
(1)Yorkshire
(2) Warwick $\quad$ (2) West Midland
(3) Warwick
(3) Birmingham
(4)Yorkshire
(4) Balham
(5) Leicester
(5) Norfolk

(1) Warrick

4

433

434 Table 8. Computation results of $Z_{1}, Z_{2}, Z_{3}$ and $Z_{4}$ obtained by the goal programming.

\begin{tabular}{|c|c|c|c|c|c|c|c|c|c|c|c|}
\hline & & Satisfact & on level & & & jective fun & tion solution & & Faci & s open & \\
\hline \# & $\mu_{1}\left(Z_{1}\right)$ & $\mu_{2}\left(Z_{2}\right)$ & $\mu_{3}\left(Z_{3}\right)$ & $\mu_{4}\left(Z_{4}\right)$ & $\begin{array}{r}\operatorname{Min} Z_{1} \\
(\mathrm{GBP})\end{array}$ & $\begin{array}{c}\operatorname{Min} Z_{2} \\
(\mathrm{Kg})\end{array}$ & $\begin{array}{c}\operatorname{Max} Z_{3} \\
(\%)\end{array}$ & $\begin{array}{c}\operatorname{Min} Z_{4} \\
\text { (h) }\end{array}$ & Farms & Abattoirs & $\begin{array}{c}\text { Run time } \\
\text { (s) }\end{array}$ \\
\hline 1 & 0.98 & 0.95 & 0.01 & 0.95 & 43540 & 741612 & 0.766 & 54.5 & $\begin{array}{l}\text { (3) Warwick } \\
\text { (5) Leicester }\end{array}$ & $\begin{array}{l}\text { (3) Birmingham } \\
\text { (4) Balham }\end{array}$ & 2 \\
\hline 2 & 0.85 & 0.83 & 0.11 & 0.82 & 43540 & 931621 & 0.766 & 54.5 & $\begin{array}{l}\text { (3) Warwick } \\
\text { (5) Leicester }\end{array}$ & $\begin{array}{l}\text { (3) Birmingham } \\
\text { (4) Balham }\end{array}$ & 2 \\
\hline 3 & 0.66 & 0.75 & 0.24 & 0.70 & 69340 & 1200987 & 0.844 & 78.5 & $\begin{array}{l}\text { (2) Warwick } \\
\text { (4) Yorkshire } \\
\text { (5) Leicester }\end{array}$ & $\begin{array}{l}\text { (2) West Midland } \\
\text { (3) Birmingham } \\
\text { (4) Balham }\end{array}$ & 3 \\
\hline 4 & 0.76 & 0.67 & 0.35 & 0.64 & 86550 & 1388987 & 0.888 & $105 . .1$ & $\begin{array}{l}\text { (2) Warwick } \\
\text { (3) Warwick } \\
\text { (5) Leicester }\end{array}$ & $\begin{array}{l}\text { (1) Warrick } \\
\text { (3) Birmingham } \\
\text { (4) Balham }\end{array}$ & 3 \\
\hline 5 & 0.65 & 0.48 & 0.46 & 0.44 & 97119 & 1578987 & 0.9 & 130.5 & $\begin{array}{l}\text { (2) Warwick } \\
\text { (3) Warwick } \\
\text { (5) Leicester }\end{array}$ & $\begin{array}{l}\text { (1) Warrick } \\
\text { (3) Birmingham } \\
\text { (4) Balham }\end{array}$ & 4 \\
\hline 6 & 0.48 & 0.48 & 0.55 & 0.39 & 124650 & 1738985 & 0.955 & 179.5 & $\begin{array}{l}\text { (2) Warwick } \\
\text { (3) Warwick } \\
\text { (5) Leicester }\end{array}$ & $\begin{array}{l}\text { (2) West Midland } \\
\text { (3) Birmingham (4) } \\
\text { Balham } \\
\text { (5) Norfolk }\end{array}$ & 3 \\
\hline
\end{tabular}



(3) Warwick
(3) Birmingham
(4) Yorkshire
(4) Balham
(5) Leicester
(5) Norfolk
(2) Warwick
(2) West Midland
(3) Warwick
(3) Birmingham
(4) Yorkshire
(4) Balham
(5) Leicester
(5) Norfolk

9
(2) Warwick
(2) West Midland
(3) Warwick
(3) Birmingham
(4) Yorkshire
(4) Balham
(5) Leicester
(5) Norfolk
(2) Warwick
(2) West Midland
(3) Warwick
(3) Birmingham
(4) Yorkshire
(4) Balham
(5) Leicester
(5) Norfolk

435 As shown in Tables 5, 7 and 8, the results are also associated with numbers and geographical 436 locations of farms and abattoirs that should be opened. For an example, solution 1 in Table 7

437 has two opened farms, which are located in Warwick and Leicester, to supply livestock to two 438 abattoirs located in Birmingham and Balham. This solution leads to a transportation and 439 implementation cost of 435,40 GBP, $\mathrm{CO}_{2}$ emissions of $740,010 \mathrm{~kg}$, an average delivery rate of $44076.6 \%$ and a distribution time of $54.5 \mathrm{~h}$. It can be seen in these tables that increasing the desired 441 value of $Z_{3}$ leads to increasing the undesired values of $Z_{1}, Z_{2}$ and $Z_{4}$.

442 The Pareto solutions can be categorized into three sections. Section 1 (solutions 1-3) shows a cost-oriented MSC network when the undesired values of $\mathrm{Z}_{1}, \mathrm{Z}_{2}$ and $\mathrm{Z}_{4}$ are increased modestly 
444 i.e., this section designs the MSC network with the lowest total transportation and

445 implementation cost, $\mathrm{CO}_{2}$ emissions and distribution time. In contrast, section 2 (solutions 4-

446 6) designs the MSC with compromise solutions. Section 3 which can be called a satisfaction-

447 oriented section (solutions 7-10) designs the MSC with the highest average delivery rate. On

448 the other hand, this section requires the decision makers to invest more money to achieve higher

449 delivery rate.

450 Fig.4 illustrates the objective values (using LP-metrics) corresponding to different $\alpha$-level. As

451 shown in Fig.4, by increasing the satisfaction level ( $\alpha$-level) it leads to an increase in the

452 undesired value of $Z_{1}, Z_{2}$ and $Z_{4}$ but an increase in the desired value of $Z_{3}$. In other words,

453 values of $Z_{1}, Z_{2}$ and $Z_{4}$ for the $\alpha_{c}$ close to 0.1 are better than levels of $\alpha$. However, decision

454 makers can vary the satisfaction level ( $\alpha$-level) based on their preferences to obtain a trade-off

455 solution.

456

457

458

459

460

461

462
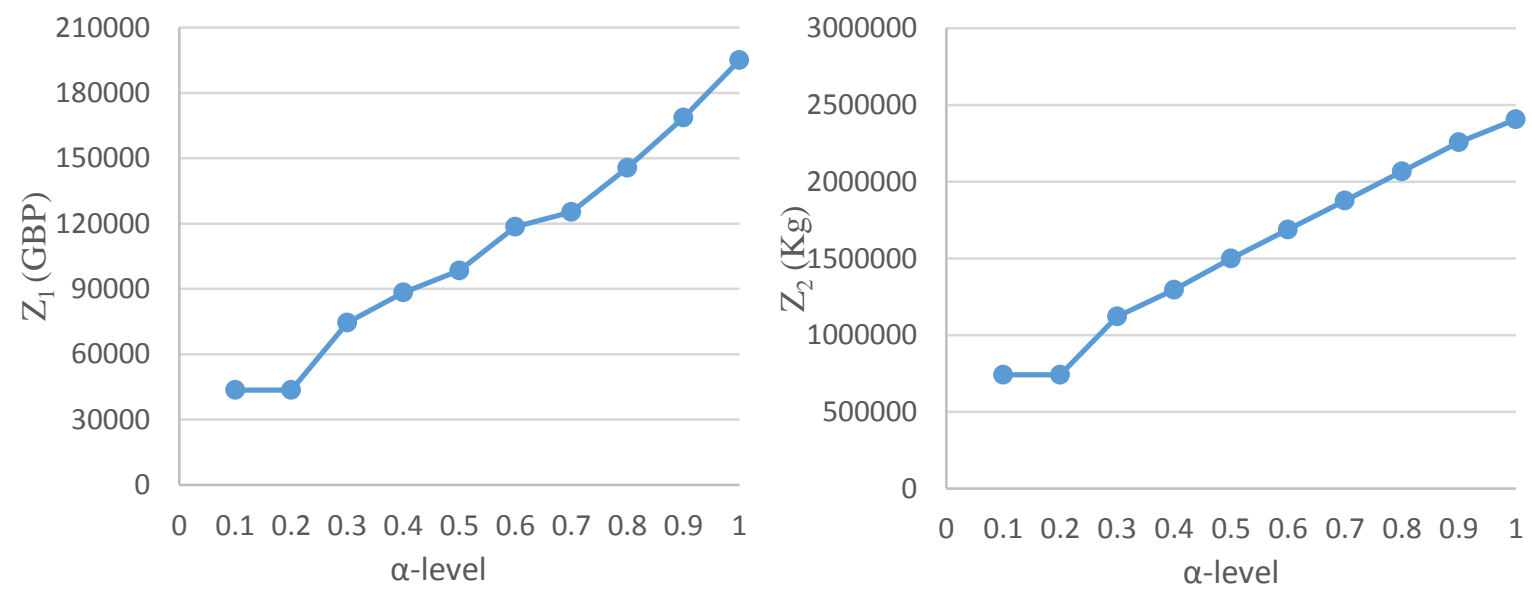

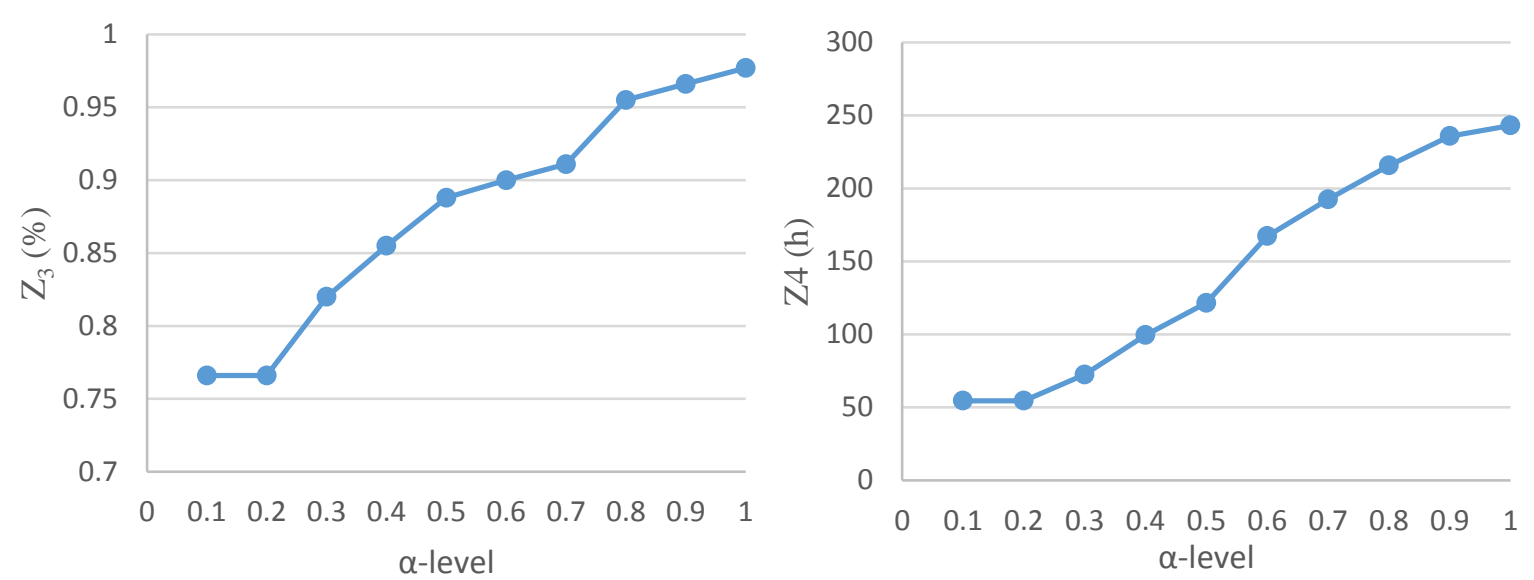

471

472 Fig. 4. $Z_{1}, Z_{2}, Z_{3}$ and $Z_{4}$ values for various $\alpha$-level.

473 Fig 5. depicts a comparison of $\mathrm{Z}_{1}, \mathrm{Z}_{2}, \mathrm{Z}_{3}$ and $\mathrm{Z}_{4}$ values obtained by three solution methods. It

474 is shown that no solution is ideal since none of the solution methods can optimize the four

475 objective functions simultaneously. However, the three methods performed well in revealing

476 the alternative Pareto solutions. The direct selection of the best Pareto solution impossible due

477 to (i) the values of the four objectives obtained by the three methods are slight different and

478 (ii) the performance of the solution methods is varied towards the others.

- LP-metrics $\square \varepsilon$-constraint $\square$ Goal programming

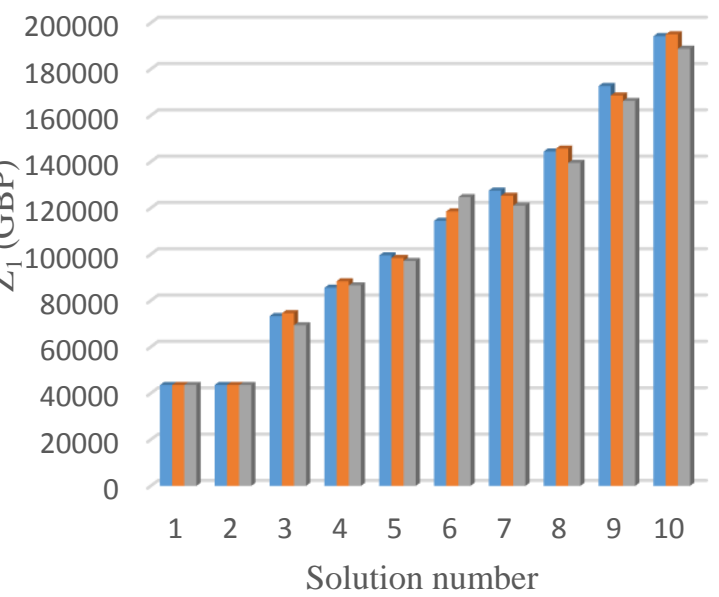

- LP-metrics $\quad$ - $\varepsilon$-constraint Goal programming

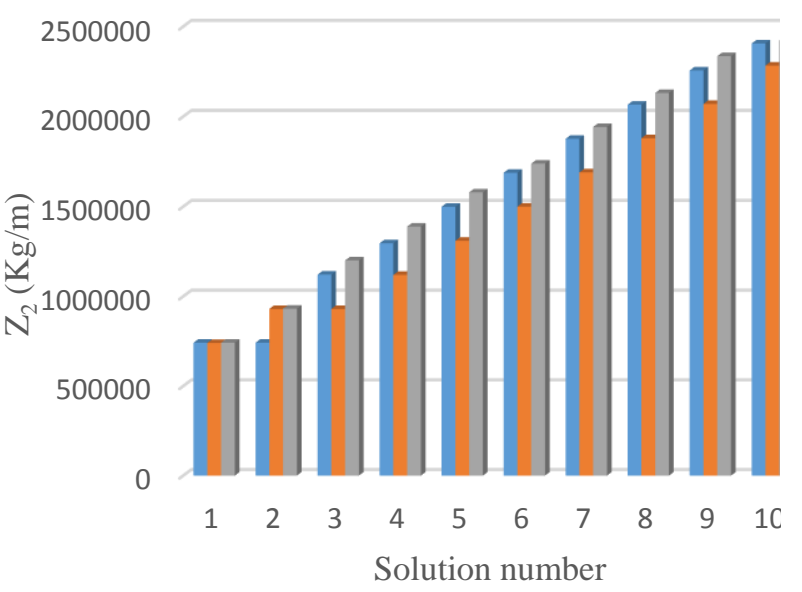




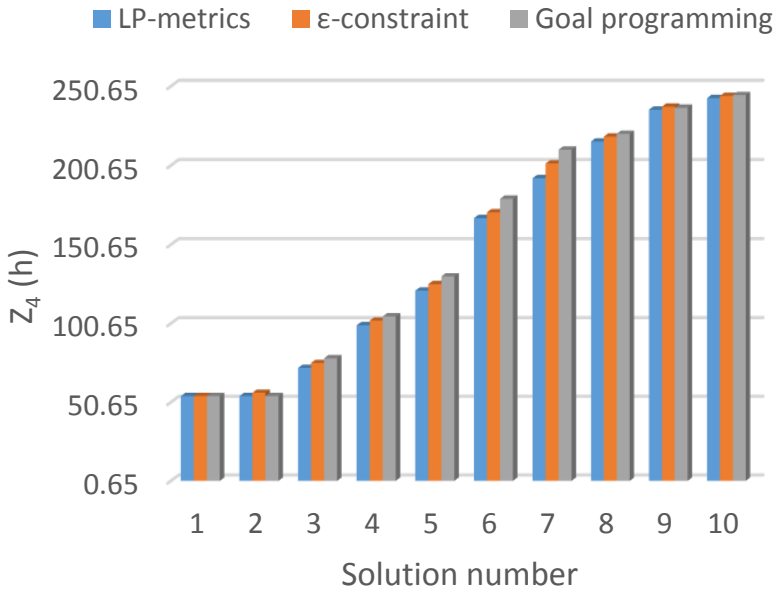

Fig. 5. Comparison of the three methods in objectives values.

Hence, the solutions can be evaluated further via the Max-Min method aiming to select the best

Pareto solution that has the minimum distance to the objectives' ideal values. As shown in

Table 7 solution 4 was chosen as the best solution as it has the closest value (3.097) to ideal objective values. Therefore, rather than the goal programming and LP-metrics, the $\varepsilon$-constraint method is more effective for this model. Besides, the run time of the $\varepsilon$-constraint method for the ten iterations was slightly faster than the goal programming and LP-metrics methods. Based on solution 4 shown in Table 7, three farms located in Warwick and Leicester were selected to supply livestock to three abattoirs located in Warwick, Birmingham and Norfolk. This solution requires a minimum total transportation and implementation cost of 88,321 GBP. It yields $\mathrm{CO}_{2}$ emissions equivalent to $1,120,010 \mathrm{Kg}$, a delivery rate up to $85.8 \%$ and a distribution time of 102.4 h. Fig. 6. illustrates the number of the selected farms and abattoirs and the optimal flow of product quantity from farms to abattoirs and from abattoirs to retailers. It shows that farm two supplies 800 livestock to abattoir five and abattoir three supplies 95 packages of meats to retailer two as in this way it gives an optimal distribution plan. Fig. 7 shows the geographical locations of these facilities. 
510

511

Farms

Abattoirs

Retailers

511

512

513

514

515

516

517

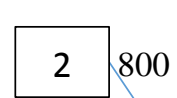

0

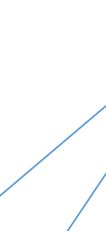

1

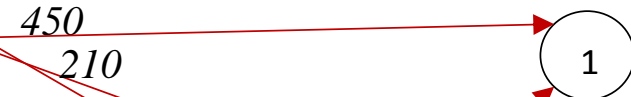

12

13
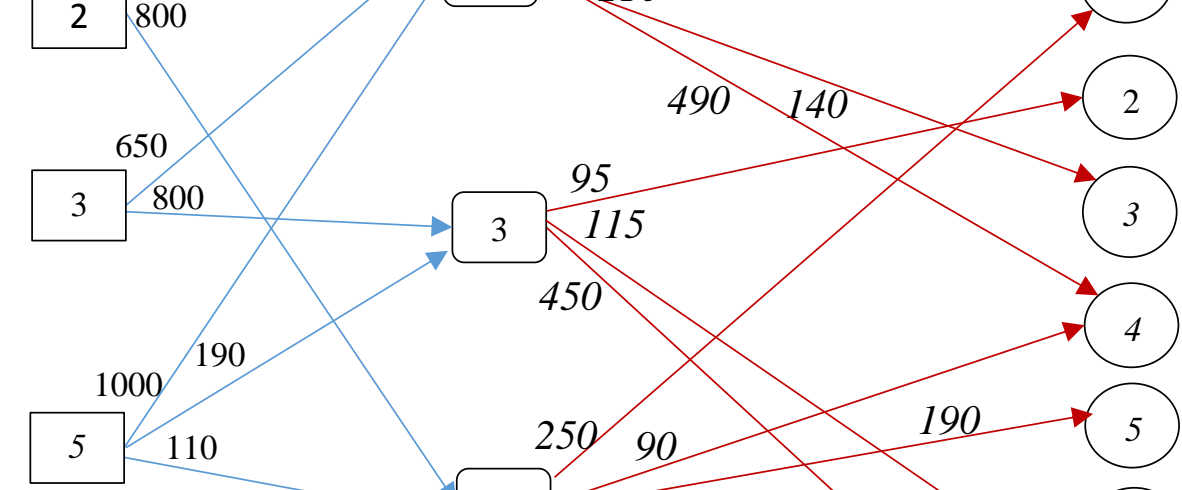

190

110
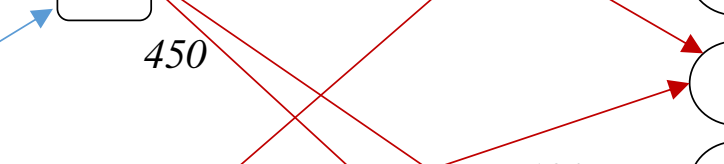

4

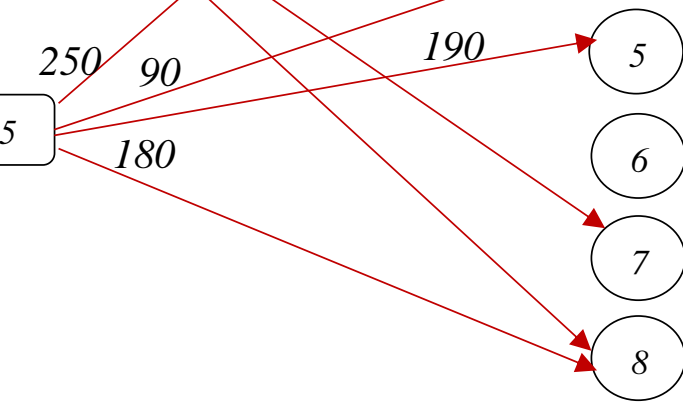

518

Livestock

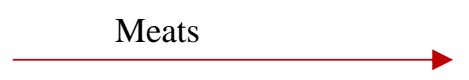

519 Fig. 6. The optimal design and distribution plan for the MSC.

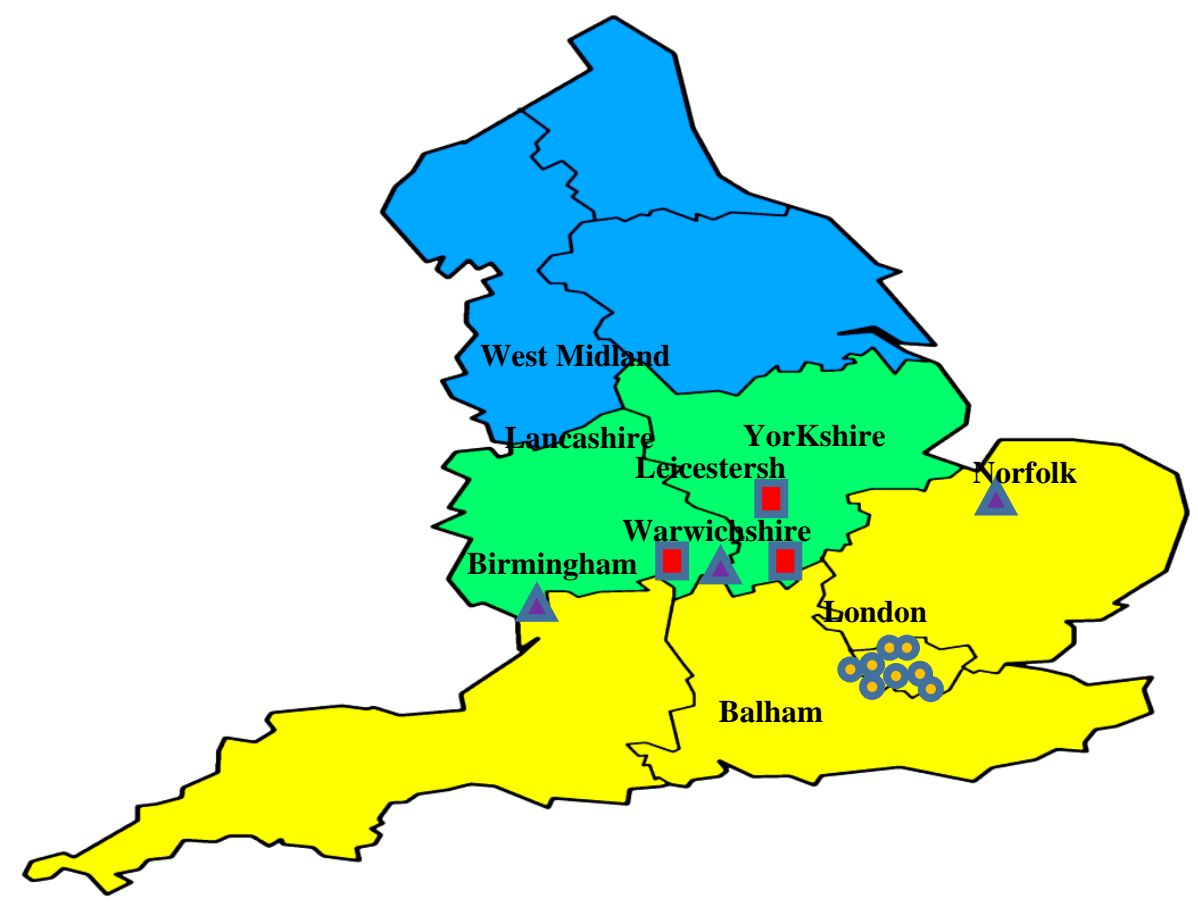

Facilities legend:
Farms
Abattoirs
Retailers 
524 Fig. 7. Geographical locations of the selected facilities for solution 4.

\section{$525 \quad 5.2$ Cost analysis}

526 Fig. 8 shows the comparative result of the total transportation and implementation cost of the 527 MSC network with or without the RFID implementation based on the eight non-inferior 528 solutions obtained from the RFID-based MSC model multi-objective model and the non RFID529 based HMSC model. It can be seen in Fig. 8 that it leads to a decrease in the total transportation 530 and implementation cost of an average 21,314 GBP after a year period of the RFID implementation into the MSC network, compared to the same MSC network without the RFID 532 implementation. As shown in Fig. 8, for solution 1, it yields a total transportation and implementation cost of 65,740 GBP of the non-RFID-based HMSC network compared to a 534 total transportation and implementation cost of 43,540 GBP of the RFID-based HMSC 535 network. For solution 5, it yields an average decrease in difference in the total transportation 536 and implementation cost of 18,998 GBP after the RFID implementation. The result shows that 537 the RFID implementation for the MSC network leads to a decrease in the transportation and 538 implementation cost of an average $18 \%$. 


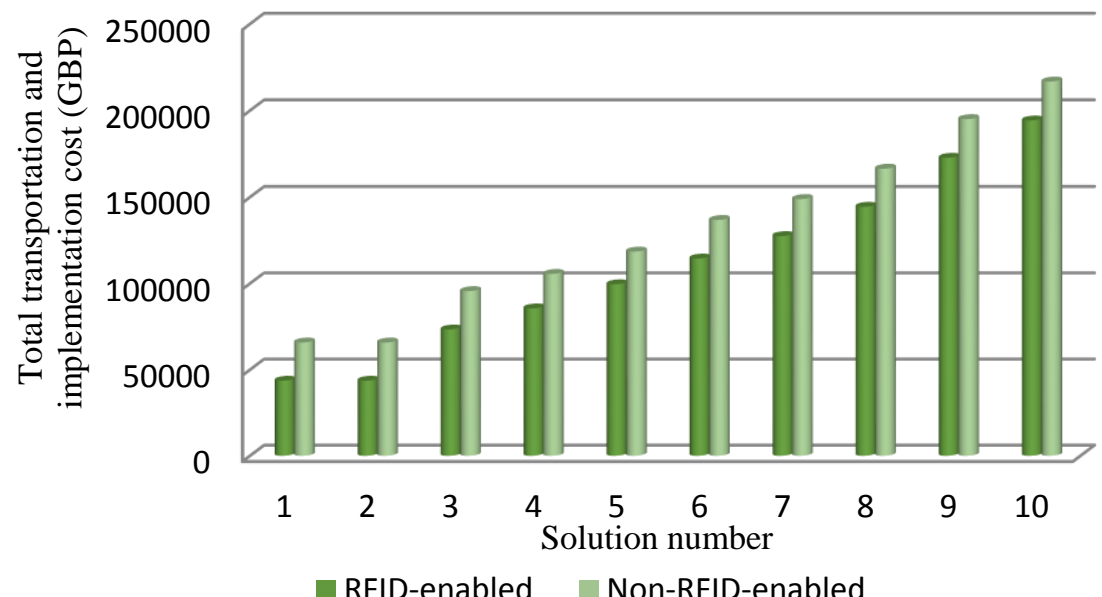

540 Figure 8. Comparative results of the total transportation and implementation cost between the 541 non-RFID-based MSC and the RFID-based MSC

\section{Conclusions}

543 This study investigated a three-echelon meat supply chain by developing a fuzzy multi544 objective programming model incorporating uncertainties aimed at the optimization of four 545 objectives which include minimization of the total transportation and implementation cost, $\mathrm{CO}_{2}$ emission and distribution time of products from farms to abattoirs and from abattoirs to retailers and maximization of the average delivery rate. Three different methods were employed to obtain Pareto solutions. The total transportation and implementation cost for the non-RFIDbased MSC was formulated as a mono-objective model aiming to presents a cost-effective analysis for the impact of the RFID implementation on a MSC. The developed fuzzy multiobjective distribution planner was applied to a case study to examine if it is robust enough to present an optimal MSC network design. The research findings concluded that the developed fuzzy multi-objective distribution planner can be used to (i) determine the numbers of facilities with locations that should be opened in response to the quantity flow of products, (ii) obtain a trade-off among the consider conflicting objectives. The result demonstrates that the $\varepsilon$ constraint method outperforms goal programming and LP-metrics. Furthermore, they proved 
557

558

559

560

561

562

563

564

565

566

567

568

569

570

571

572

573

574

575

576

577

578

579

580

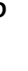

that the RFID implementation on a MSC leads to a decrease in the total transportation and implementation cost of an average 21,314 GBP after a year period.

A number of other avenues are recommended in order to improve the developed FMOPM, such as to solve the multi-objective optimization problem using meta-heuristic algorithms such as NSGA-II, and MOPSO which may perform better for a large-size problem in a reasonable time. Also, this research may be extended for a multi-product multi-period FSC. Lastly, it would also be an interesting research direction to formulate the maximization of meat quality as an objective function.

\section{Acknowledgements}

The authors would like to express their gratitude to the Higher Committee for Education Development (HCED) in Iraq for the financial support in this study. Also, the authors would like to thank the anonymous referees whose thorough reviews and insightful comments made a valuable contribution to this article.

0

1

2

3

74

575

\section{Appendix}

Table I. Abbreviations

\begin{tabular}{|c|c|}
\hline Abbreviation & Definition \\
\hline SC & Supply chain \\
\hline MSC & Meat supply chain \\
\hline
\end{tabular}




\begin{tabular}{|c|c|}
\hline FMOPM & Fuzzy multi-objective programming model \\
\hline RFID & Radio frequency identification \\
\hline FSCs & Food supply chains \\
\hline SCNs & Supply chain networks \\
\hline FSCND & Food supply chain network design \\
\hline LP & Linear programming \\
\hline
\end{tabular}

581

582

583

584

585

586

587

588

589

590

591

592

593

594

595

596

597

598

599

600

601

\section{References}

Accorsi, R., Cholette, S., Manzini, M., Pini, C., \& Penazzi, S. 2016. The land-network problem: ecosystem carbon balance in planning sustainable agro-food supply chains, Journal of Cleaner Production, 112, 158-171.

Al-e-hashem, M.S.M.J., Malekly, H., Aryanezhad, M.B. 2011. A multi-objective robust optimization model for multi-product multi-site aggregate production planning in a supply chain under uncertainty, Int. J. Production Economics, 134, 28-42.

Aliev R.A., Fazlollahi, B., Guirimov B.G. and Aliev, R.R. 2007. Fuzzy-genetic approach to aggregate production-distribution planning in supply chain management. Information Sciences, 177, 4241-4255

Bortolini, M., Faccio, M., Ferrari, M., Gamberi, M., \& Pilati, F. 2016. Fresh food sustainable distribution: cost, delivery time and carbon footprint three-objective optimization, Journal of Food Engineering, 174, 56-67.

Davis, T. 1993. Effective supply chain management, Sloan Manag. Rev. 34, 35-46.

Ehrgott, M. (2005). Multicriteria Optimization. $2^{\text {nd }}$ ed., Springer, New York.

Kannan D., Khodaverdi R., Olfat L., Jafarian A. and Diabat A. 2013. Integrated fuzzy multi criteria decision making method and multi-objective programming approach for supplier 
602

603

604

605

606

607

608

609

610

611

612

613

614

615

616

617

618

619

620

621

622

623

624

625

626

selection and order allocation in a green supply chain. Journal of Cleaner Production 47, 355-367.

Fattahi M., Mahootchi M., Govindan k. 2015. Dynamic supply chain network design with capacity planning and multi-period pricing. Transport. Res. Part E: Logist. Transport. Rev. 81, 169-202.

Fritz, M., \& Schiefer, G. (2009). Tracking, tracing, and business process interests in food commodities: a multi-level decision complexity. International Journal Production Economics, 117, 317-329.

García-Flores, R., Higgins, A., Prestwidge, D., \& McFallan, S. 2014. Optimal location of spelling yards for the northern Australian beef supply chain. Computers and Electronics in Agriculture, 102, 134-145.

Gholamiana, N., Mahdavia, I., Tavakkoli-Moghaddamb, R., \& Mahdavi-Amiric, N. 2015. Comprehensive fuzzy multi-objective multi-product multi-site aggregate production planning decisions in a supply chain under uncertainty, Applied soft computing, 37, 585607.

Harris, I., Mumford, C.L., \& Naim, M.M. 2014. A hybrid multi-objective approach to capacitated facility location with flexible store allocation for green logistics modeling. Transportation Research Part E, 66, 1-22.

HMC, UK. (2010). http://www.halalhmc.org/ , Available: http://www.halalhmc.org/test$\underline{\text { demo.htm }}$. (accessed October 26, 2014).

Jiménez López, M., Arenas, M., Bilbao, A. \& Rodriguez, M.V. (2007). Linear programming with fuzzy parameters: An interactive method resolution. Eur. J. Oper. Res., 177, 15991609.

Liang, T.F. 2006. Distribution planning decisions using interactive fuzzy multiobjective linear programming, Fuzzy Sets Syst. 157, 1303-1316. 
Liu, S. \& Papageorgiou, L.G. 2013. Multi objective optimisation of production, distribution and capacity planning of global supply chains in the process industry, Omega 41, 369-382.

Liu, S.T. \& Kao, C. 2004. Solving fuzzy transportation problems based on extension principle, European Journal of Operational Research, 153, 661-674.

Mattevi, M., \& Jones A.J. 2016. Traceability in the food supply chain: Awareness and attitudes of UK Small and Medium-sized Enterprises, Food Control, 64, 120-127.

Pagell, M., \& Wu, Z. 2009. Building a more complete theory of sustainable supply chain management using case studies of 10 exemplars. J. Supply Chain Manag. Glob. Rev. Purch. Supply, 45, 37-56.

Paksoy, T., Pehlivan, N.Y., \& Özceylan, E., 2012. Application of fuzzy optimization to a supply chain network design: case study of an edible vegetable oils manufacturer, Applied Mathematical Modelling (SCI-expanded), 36 (6), 2762-2776.

Paksoy, T., Pehlivan, N.Y., \& Özceylan, E., 2012. Fuzzy multi objective optimization of green supply chain network with risk management of included environmental hazards, Human and Ecological Risk Assessment (SCI), 18 (5), 1121-1152.

Pasandideh, S.H.T., Niaki, S.T.A, Asadi, K. 2015. Optimizing a bi-objective multi-product multi-period three echelon supply chain network with warehouse reliability, Expert Systems with Applications, 42, 2615-2623.

Peidro, D., Mula, J., Poler, R., Verdegay, J. 2009. Fuzzy optimization for supply chain planning under supply, demand and process uncertainties, Fuzzy Sets Syst. 160, 2640-2657.

Pishvaee, S. M., \& J. Razmi. 2012. Environmental Supply Chain Network Design Using Multiobjective Fuzzy Mathematical Programming. Applied Mathematical Modelling, 36 (8), $3433-3446$. 
Petrovic, Dobrila, Rajat Roy, and Radivoj Petrovic. 1998. Modelling and Simulation of a Supply Chain in an Uncertain Environmentî, European Journal of Operational Research, 109, 299-309.

Qin, Z., Ji, X. 2010. Logistics network design for product recovery in fuzzy environment, Eur. J. Oper. Res. 202, 479-490.

Robinson, D.R., \& Wilcox, S. 2008.The greening of supply chains. Supply Chain Manag. Rev., $12,61-66$.

Rong, A., Akkerman, R., \& Grunow, M. 2011. An optimization approach for managing fresh food quality throughout the supply chain, Int. J. Prod. Econ., 131, 421-429.

Özceylan, E., \& Paksoy, T. 2013. Fuzzy multi objective linear programming approach for optimizing a closed-loop supply chain network, International Journal of Production Research (SCI), 51 (8), 2443-2461.

Özceylan., E., \& Paksoy, T. 2014. Interactive Fuzzy Programming Approaches to the Strategic and Tactical Planning of a Closed-Loop Supply Chain under Uncertainty, International Journal of Production Research (SCI), 52 (8), 2363-2387.

Sahar, V., Arijit B., \& Byrne, P.J. 2014. A case analysis of a sustainable food supply chain distribution system-A multi-objective approach, International Journal of Production Economics, 152, 71-87.

Sakawa, M., Nishizaki, I., Uemura, Y. 2001. Fuzzy programming and profit and cost allocation for a production and transportation problem, European Journal of Operational Research, $131,1-15$.

Selim H., Araz C., Ozkarahan I. 2008. Collaborative production-distribution planning in supply chain: A fuzzy goal programming approach. Transport. Res. Part E: Logist. Transport. Rev. 44, 396-419. 
674 Shih, L.H. 1999. Cement transportation planning via fuzzy linear programming, International 675 Journal of Production Economics, 58, 277-287.

676 Snyder, L. 2006. Facility location under uncertainty: A review. IIE Trans 38, 537-554.

677 Talaei, M., Farhang B., Pishvaee, M.S., Bozorgi-Amiri, A., \& Gholamnejad, S. 2015. A robust 678 fuzzy optimization model for carbon-efficient closed-loop supply chain network design problem: A numerical illustration in electronics industry, Journal of Cleaner Production, 15,

Teimoury, E., Nedaei, H., Ansari, S., \& Sabbaghi, M. 2013. A multi-objective analysis for import quota policy making in a perishable fruit and vegetable supply chain: A system dynamics approach. Computers and Electronics in Agriculture, 93, 37-45.

Torabi, S. A., \& Hassini, E. 2008. An Interactive Possibilistic Programming Approach for 685 Multiple Objective Supply Chain Master Planning. Fuzzy Sets and Systems, 159 (2), 193214.

Vidal, C.J., \& Goetschalckx, M. 1997. Strategic production-distribution models: a critical review with emphasis on global supply chain models. European Journal of Operational Research, 98, 1-18.

Wang, H.F., Hsu, H.W. 2010. Resolution of an uncertain closed-loop logistics model: an application to fuzzy linear programs with risk analysis, J. Environ. Manage., 91, 2148-62.

Wang, J., Shu, Y.-F., 2005. Fuzzy decision modeling for supply chain management. Fuzzy Sets and Systems 150, 107-127.

Zarandi, M. H. F., Sisakht, A. H., \& Davari, S. 2011. Design of a closed-loop supply chain (CLSC) model using an interactive fuzzy goal programming. The International Journal of Advanced Manufacturing Technology, 56, 809-821. 